A nine-year-old male was treated with a positive practice procedure for inappropriate out-of-seat behavior in the classroom. Because both subject and teacher lived in an isolated rural environment, professional involvement was unavoidably restricted to a long-distance consultation-type format. Contingencies were applied by the subject's teacher and results were evaluated by means of a single-subject reversal design. Introduction and removal of the positive practice procedure appeared to have a clear and systematic effect upon the frequency of target behavior occurrence. Moreover, behavioral improvements were maintained three and one-half months following a Positive Practice-Matching condition in which the subject self-monitored, matched, and earned group rewards for the entire class. These results were discussed with regard to problem-specific consultation and the situational constraints often imposed by rural environments.

\title{
Behavior Modification by Long-Distance
}

\author{
Demonstration of Functional Control over \\ Disruptive Behavior in a Rural Classroom Setting
}

\author{
PHILIP H. BORNSTEIN \\ University of Montana \\ SCOTT B. HAMILTON \\ University of Oregon \\ RANDAL P. QUEVILLON \\ University of Oklahoma
}

One of the major strengths of behavior modification technology has been its ease of application by members of the nonprofessional mental health community. Most behavioral interventions with children, in fact, have involved the training of parents and/or teachers in the application of elementary behavior change procedures (Guerney, 1969; Hall, 1971; Rinn,

\footnotetext{
AUTHORS' NOTE: Requests for reprints should be addressed to Philip $H$. Bornstein, Department of Psychology, University of Montana, Missoula, Montana 59812. Portions of this paper were presented at the Tenth Annual Convention of the Association for Advancement of Behavior Therapy, December 3-5, 1976 , New York.
} 
Vernon, \& Wise, 1975). However, situational constraints imposed by rural environments often limit the amount of professional involvement available for direct training of potential change-agents. For example, in cases where the target child and the adult agent reside considerable distances from mental health facilities, face-to-face consultation on a frequent basis may be impossible. While programmed texts (Patterson, 1971; Walker \& Buckley, 1973), workshops (Hall, 1971), and taped cassette courses (Bornstein, 1975) may have potential applicability in rural settings, previous research has indicated that general training may fail to provide change-agents with the requisite skills necessary for specific behavioral intervention (Bowles \& Nelson, 1976; Gardner, 1972). In rural settings, therefore, problem-specific consultation via phone and mail contacts may provide an important alternative to the general training model.

The purpose of the present investigation was twofold: (a) to demonstrate the applicability of behaviorally oriented consultation by long-distance, and (b) to illustrate the utility of a positive-practice procedure (Azrin \& Powers, 1975; Foxx \& Azrin, 1972; Epstein, Doke, Sajwaj, Sorrel, \& Rimmer, 1974) in promoting maintenance of behavioral improvements over an extended follow-up period.

\section{METHOD}

\section{Subject and Teacher}

The teacher, Ms. J., had contacted the senior author for consultation regarding the disruptive behavior of a third grade pupil. Ms. J. had been teaching for approximately five years in a rural Montana town and recently completed, under the direction of the senior author, a university-level course on elementary behavior-change principles. Since Ms. J. lived and worked approximately 500 miles from the university, all communication with her was unavoidably restricted to phone calls and letters mailed via routine postal services. 
The subject, Herbie, was a nine-year-old white male who had been found to be functioning in the normal range of intellectual abilities. Informal observations by teachers and school principal indicated that the central problem appeared to be one of out-ofseat behavior. Apparently, when in his seat, Herbie presented no major problem to classroom decorum. However, once out of his seat, he would become noncompliant, aggressive, noisy, and quite disruptive to other students. Moreover, Herbie's academic work and relationships with other children appeared to be deteriorating (e.g., no longer being included in extracurricular activities) as a result of his continual disruptive behavior.

\section{Experimental Design}

The current investigation employed an A-B-A'-B-C reversal design as a means of demonstrating functional control over the target (i.e., out-of-seat) behavior. Following the four initial phases (i.e., A-B-A'-B), a fifth condition (i.e., Positive Practice III-Matching) was included to increase the probability of maintaining behavior change following program termination. Each of the first four phases lasted for five days, while the fifth phase was in effect for 55 experimental days. Follow-up data were collected during a week-long period, six months following the initiation of baseline.

\section{Dependent Variable and Observational Recording}

Out-of-seat behavior was defined as movement of the child from his chair when not permitted or requested by the teacher; no part of the child's body could be touching the chair (O'Leary, Kaufman, Kass, \& Drabman, 1970). Although Herbie spent approximately five hours per day in his "home" classroom, behavioral observations and treatment interventions were conducted solely during a two-hour period in the morning when activities were of a structured nature. Herbie's teacher, Ms. J., was the primary data collection observer, with her aide, Ms. R., 


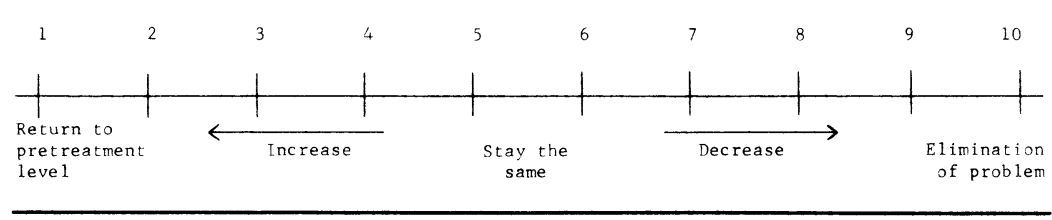

Figure 1.

serving as a covert reliability checker. Both Ms. J. and Ms. R. were present and in the room throughout the course of the investigation. Observations, by means of frequency tally cards unobtrusively placed on the teachers' desks were made by Ms. J. on a daily basis, with Ms. R. independently observing Herbie's behavior twice a week (on random days) across all experimental phases. When a reliability check was made, the average of the two frequency counts served as the data point. Although Ms. J. was informed that reliability checks were to be conducted, she was not aware of exactly when they were to occur (see Taplin \& Reid, 1973). This was accomplished by having the senior author mail instructions directly to Ms. R. without working through Ms. J. as an intermediary.

\section{Expectancy Control}

Previous research (Hamilton, Quevillon, \& Bornstein, in press) has indicated that reversal-rationales commonly used in A-B-A-B designs may provide change-agents with differential reversal-to-baseline expectations. In order to examine and control for the possibility of such behavioral expectations in the present study, (a) Ms. J. was asked to rate, on the scale appearing in Figure 1, the amount of directional change in out-of-seat behavior expected during three of the initial A-B$A^{\prime}-B$ phases, and (b) a counter-expectancy reversal-rationale was presented during the DRO-reversal condition. Therefore, the purpose of the expectancy control manipulation was an attempt to provide consistent expectations for change across experimental conditions. 
General Procedure

Baseline I. During this condition, behavioral observations were conducted, but no experimental operations were implemented. Ms. J. and her aide were instructed simply to respond to Herbie's out-of-seat behavior as before (i.e., "as each infraction occurs, remind him that leaving his seat without permission is not allowed").

Positive Practice I. At the beginning of this phase, Ms. J. was instructed to "personally inform Herbie that leaving his seat without permission is not only against the rules, but that each infraction will result in three minutes being deducted from his lunch/recess hour."' During the noon period (if infractions had occurred), Herbie was then required to remain in the classroom and perform the following positive practice exercises: (a) recite, upon request, the classroom rule, "do not get out of your seat without permission," and (b) raise hand and, upon being acknowledged by the teacher, ask permission to leave seat. This entire sequence was repeated until the full positive practice time had elapsed. If Herbie refused to comply, the teacher was instructed to merely reiterate her requests in a firm voice and note that if Herbie continued acting uncooperatively, additional time would be added to the positive practice period (such refusals occurred only twice throughout the entire program and were successfully dealt with in the prescribed manner). Approximately six of the above positive practice exercises were completed during each three-minute period.

DRO-reversal. As part of the expectancy control manipulation, Ms. J. was informed just prior to the initiation of the DROreversal phase that "although the frequency of target behavior has declined considerably, the positive practice procedure is usually only effective for the quick suppression of behavior." Thus, she was led to believe that, in order to generate further behavioral reductions, "the current program was to be terminated immediately." An inert treatment and counterexpectancy 
rationale (see Hamilton et al., in press) was then provided in which Ms. J. was instructed to attend now to the "underlying cause" of the problem (i.e., feelings of insecurity). In addition, as discussed by Kazdin (1975), a DRO-reversal was utilized as an alternative to simple contingency withdrawal. Herbie was therefore informed that, "although permission is still required to leave your seat, infractions will no longer result in positive practice exercises." Instead, whenever an out-of-seat behavior occurred, Ms. J. (a) reminded Herbie that leaving his seat without permission was not allowed, and (b) verbally praised his performance with regard to current classroom behavior.

Positive Practice II. Ms. J. was informed that since the target behavior had not responded to the previous "treatment" condition, it would be necessary to reimplement positive practice exercises. This condition was identical to Positive Practice I.

Positive Practice III-Matching. Herbie was told that positive practice exercises would continue as before, except now both he and the teacher would be responsible for counting out-of-seat behaviors. Herbie received no systematic training in monitoring his out-of-seat behavior aside from a definitional statement provided by Ms. J. Daily teacher and student records were compared just prior to the recess hour; if Herbie's score was within one of that recorded by the teacher, he was to earn an extra 15 minutes "recess-reward" time for the entire class. Additionally, Ms. J. was instructed to "praise Herbie for accurate self-monitoring and provide feedback whenever inaccuracy occurs." When incidents of out-of-seat behavior did occur, teacher records were used as the basis for positive practice exercises. Following three consecutive days of "recessreward" matching, the process was faded such that the "recessreward" contingency occurred over progressively leaner schedules of reinforcement (i.e., VI-1, VI-2, VI-3, VI-5, VI-10, VI-20), while matching without the group reward continued on a daily basis. Thus, self-recording continued during the entire 
55-day period, with group rewards only being earned on "recessreward" days unknown in advance to Herbie.

On the final day of Positive Practice III-Matching, Herbie was congratulated in front of the entire class for his excellent performance. Furthermore, it was explained that since he was now "entirely capable of controlling out-of-seat behavior, there would no longer be a need for self-recording or positive practice exercises."

Follow-up. Behavioral observations were conducted for one week, six months following the initiation of baseline (i.e., three and one-half months after the termination of the previous experimental condition).

\section{RESULTS}

\section{Rellability}

The level of observer agreement for each experimental phase (calculated by dividing the smaller frequency by the larger frequency) was: Baseline $I=.95$, Positive Practice $I=.90$, DRO-reversal $=.90$, Positive Practice II $=.90$, Positive Practice III-Matching $=.79$, Follow-up $=.83$. The overall level of observer agreement was .88 .

During the Positive Practice III-Matching condition, Herbie was given the opportunity to self-monitor out-of-seat behaviors. Results indicated that $92 \%$ of his self-ratings were within one out-of-seat behavior of that recorded by Ms. J., and $89 \%$ were within one out-of-seat behavior of that recorded by Ms. R. Moreover, $83 \%$ of his self-ratings perfectly matched those of Ms. J., and $78 \%$ were in perfect agreement with Ms. R.

\section{Expectancy Control Manipulation}

As a measure of behavioral expectation, Ms. J. had been asked to complete a 10-point Likert-type scale prior to Positive 


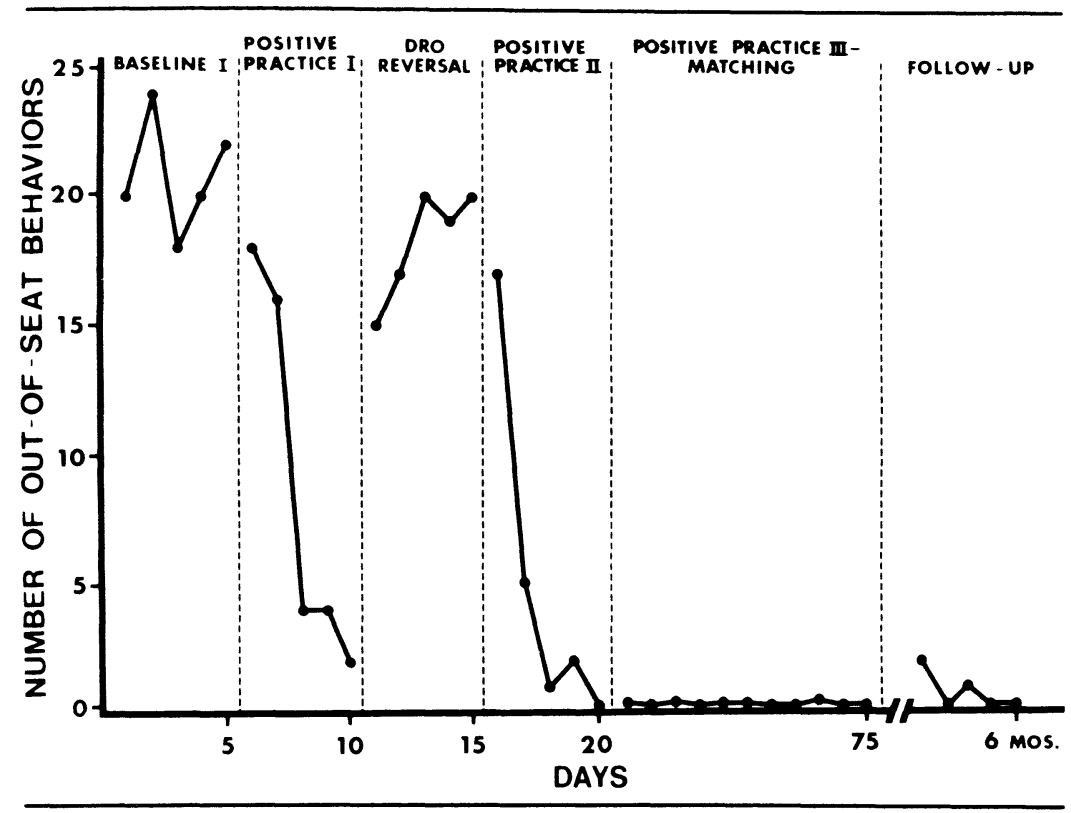

Although Positive Practice III-Matching actually lasted for $\mathbf{5 5}$ days, only 11 data points are presented. These data points represent the mean number of out-of-seat behaviors per day for the 11 weeks of this experimental period.

Figure 2: Number of Out-of-Seat Behaviors Across the Six Experimental Phases.

Practice I, II, and DRO-reversal conditions. On all three occasions she circled a score of 8 , indicating a firm and consistent expectation for target behavior decrement across intervention, reversal, and reintervention phases. These results suggest that the reversal instructions presented prior to the DROreversal phase were effective in producing a reversal-to-baseline counterexpectancy as well as consistent expectations for change across experimental conditions.

\section{Out-of-Seat Behavior}

Figure 2 represents the number of out-of-seat behaviors occurring across experimental periods. The mean number of 
daily out-of-seat behaviors across the six experimental phases was: Baseline $\mathrm{I}=20.8$, Positive Practice $\mathrm{I}=8.8$, DRO-reversal $=18.2$, Positive Practice II $=5.0$, Positive Practice III-Matching $=.1$, and Follow-up $=.7$. Moreover, baseline out-of-seat behaviors were reduced 57.7\% during Positive Practice I, 76\% during Positive Practice II, and 99.5\% during Positive Practice III-Matching. Finally, although a frequency measure was used as the sole basis for judging treatment efficacy, Ms. J. did not indicate increases in duration of target behavior occurrences over time.

\section{DISCUSSION}

The results of the present investigation clearly demonstrate the utility and effectiveness of a positive practice procedure applied through a long-distance consultation format. Furthermore, through the use of an A-B-A'-B-C reversal design and an expectancy control manipulation, changes in the target behavior were demonstrated to be a direct function of the intervention strategy utilized. This research thus clearly supports prior studies using the positive practice technique (e.g., Azrin \& Powers, 1975). Moreover, through the utilization of the Positive Practice IIIMatching condition, behavior change was maintained six months following the initiation of baseline. Given that behavior modifiers have only recently begun to emphasize the importance of generalizable behavioral changes (Keeley, Shemberg, and Carbonell, 1976), these findings would appear to be particularly relevant. Certainly, a variety of factors may have contributed to the maintenance effects obtained (e.g., peer reinforcement of appropriate behavior, mediational self-evaluations, and so on); however, since teacher behaviors were not assessed across the various phases of the investigation, there remains a possibility that teacher responses (e.g., praise, proximity, and the like) may have covaried with experimental conditions. Future research should, therefore, attempt to uncover the active maintenanceenhancing ingredients within the treatment package and, in addition, collect data with regard to both subject and teacher behaviors. 
The purpose of the present investigation, however, was not solely to further verify the effectiveness of the positive practice procedure, per se. Rather, the primary goal was to explore the applicability of behavioral technology in situations (e.g., rural environments) where traditional consultation-type activities are simply impractical. Recent research (Bowles \& Nelson, 1976) has indicated that general training in the application of behavioral principles may not be sufficient to shape effective behaviors on the part of change-agents. Problem-specific consultation by long-distance, however, may prove to be a viable alternative in providing the direct instruction necessary for the effective implementation of change strategies. A number of limitations should be considered prior to promoting acceptance of a long-distance consultation-type format, however. First, how accurate is a primary observer's report of target behavior frequency? As evidenced by the present investigation, this problem clearly is not insurmountable. Compelling counterexpectancy, reversalto-baseline rationales, and covert reliability checks are just a few of the many potential methodological strategies available to applied researchers interested in insuring unambiguous interpretation of intervention effects. Second, when consulting via longdistance, caution must be exercised so as to guard against impropriety and the impersonalization of services (American Psychological Association, 1963). While behavior modifiers have long recognized the advantages of a triadic-based model (Tharp \& Wetzel, 1969), clinicians must receive some assurances, as was indicated above, that trained and responsible change-agents are available for the conduct of such programs in a thoroughly professional manner. Finally, in that the present results were obtained using a single-subject experimental design, generalizability of the findings must remain a question. Ease of implementation and the cost-benefit factors of long-distance consultation, however, would appear to warrant its continued examination and refinement via programmatic investigations in the area. Future researchers might, therefore, devote their efforts toward systematic experimental replication with additional teachers and families. 


\section{NOTE}

1. Because the positive practice procedure created a situation in which Herbie could potentially miss a significant portion of his lunch/recess hour, ethical responsibility dictated that parental permission be obtained before conducting the present research. Upon being informed of the proposed program, Herbie's parents readily consented to his full participation.

\section{REFERENCES}

American Psychological Association. Ethical standards of psychologists. American Psychologist, 1963, 18, 56-60.

Azrin, N. A., \& Powers, M. A. Eliminating classroom disturbances of emotionally disturbed children by positive practice procedures. Behavior Therapy, 1975, 6, 525-534.

Bornstein, P. H. Behavior control in the classroom: Theory, research, and practice. Missoula: University of Montana Division of Continuing Education, 1975. (audio cassette series)

Bowles, P. E., \& Nelson, R. O. Training teachers as mediators: Efficacy of a workshop versus the bug-in-the-ear technique. Journal of School Psychology, 1976, 14, 15-26.

Epstein, L. H., Doke, L. A., Sajwaj, T. E., Sorrel, S., \& Rimmer, B. Generality and side effects of overcorrection. Journal of Applied Behavior Analysis, 1974, 7, 385-390.

Foxx, R. M., \& Azrin, N. A. Restitution: A method of eliminating aggressive-disruptive behavior of retarded and brain damaged patients. Behaviour Research and Therapy, 1972, 10, $15-20$.

Gardner, J. M: Teaching behavior modification to nonprofessionals. Journal of Applied Behavior Analysis, 1972, 5, 517-521.

Guerney, B. B. Psychotherapeutic agents: New roles for non-professionals, parents and teachers. New York: Holt, Rinehart, and Winston, 1969.

Hall, R. V. Training teachers in classroom use of contingency management. Educational Technology, 1971, 11, 33-38.

Hamilton, S. B., Quevillon, R. P., \& Bornstein, P. H. Reversal-to-baseline: Demonstration of functional control or expectancy of therapeutic loss? Journal of Behavior Therapy and Experimental Psychiatry, in press.

Kazdin, A. E. Behavior modification in applied settings. Homewood, Ill.: Dorsey Press, 1975.

Keeley, S. M., Shemberg, K. M., \& Carbonell, J. Operant clinical intervention: Behavior management or beyond? Where are the data? Behavior Therapy, 1976, 7, 292-305.

O'Leary, K. D., Kaufman, K. F., Kass, R. E., \& Drabman, R. S. The effects of loud and soft reprimands on the behavior of disruptive students. Exceptional Children, 1970, 37, 145-155.

Patterson, G. R. Families: Applications of social learning to family life. Champaign, Ill.: Research Press, 1971. 
Rinn, R. C., Vernon, J. C., \& Wise, M. J. Training parents of behaviorally-disordered children in groups: A three years' program evaluation. Behavior Therapy, 1975, 6, 378-387.

Taplin, P. S., \& Reid, J. B. Effects of instructional set and experimenter influence on observer reliability. Child Development, 1973, 44, 547-554.

Tharp, R. G., \& Wetzel, R. J. Behavior modification in the natural environment. New York: Academic Press, 1969.

Walker, H. M., \& Buckley, N. K. Token reinforcement techniques. Eugene, Oregon: E-B Press, 1973.

Philip H. Bornstein is Associate Professor of Clinical Psychology at the University of Montana. His current research interests include behavioral assessment in marital interaction, the effects of self-monitoring, and the clinical practice of behavior therapy. His most recent papers have appeared in Journal of Applied Behavior Analysis, Journal of Behavior Therapy and Experimental Psychiatry, Journal of Consulting and Clinical Psychology, and Behavior Therapy.

Scott B. Hamilton recently completed his doctoral training in clinical psychology at the University of Montana and is currently on internship at the University of Oregon Health Sciences Center. His research interests include broad-spectrum behavioral approaches to smoking cessation, methodological issues in selfcontrol, and the effects of demand characteristics on the outcome of behavior therapy. Several of his recent articles have and will be appearing in the Journal of Behavior Therapy and Experimental Psychiatry, Professional Psychology, Cognitive Therapy and Research, and Journal of Consulting and Clinical Psychology.

Randal P. Quevillon is currently an intern at the University of Oklahoma Health Sciences Center. His research interests include cognitive behavior therapy, behavioral self-control, and self-monitoring. His most recent papers have appeared in Journal of Applied Behavior Analysis, Journal of Behavior Therapy and Experimental Psychiatry, and Psychological Record. 